\title{
INTERSECÇÕES ENTRE O ANALFABETISMO E AS INSTITUIÇÕES SACROSSANTAS NO JORNAL O EXEMPLO (PORTO ALEGRE, RS, 1916-1930)
}

\author{
INTERSECTIONS BETWEEN ILLITERACY AND SACROSANCT \\ INSTITUTIONS IN THE "O EXEMPLO" JOURNAL \\ (PORTO ALEGRE, RS, 1916-1930)
}

Ricardo Costa de Sousa Universidade do Oeste de Santa Catarina ricardo_lut@hotmail.com

\section{RESUM0}

O texto tem a intenção de descrever as "intersecções entre o analfabetismo e as instituições sacrossantas no jornal O Exemplo, impresso publicado em Porto Alegre, estado do Rio Grande do Sul (19161930)". O recorte temporal reside na recorrência da temática do analfabetismo e, se insere no campo da História da Alfabetização e da História da Educação, sob os pressupostos teóricos e metodológicos da História Cultural. Esse pressuposto sugere prescrutar os indícios, os vestígios, as lacunas, as ausências e as representações que foram construídas em um determinado contexto. O problema, inspirado na descrição densa de Geertz (2008), reside na seguinte pergunta: como o analfabetismo torna-se um discurso corrente nas páginas do jornal O Exemplo a partir das instituições sacrossantas: família, sociedade e pátria? O texto indicou que o jornal O Exemplo empreendeu uma série de esforços para que as pessoas analfabetas procurassem meios de instruírem-se para o bem do país e progresso da nação.

Palavras-chave: Jornal O Exemplo. Instituições sacrossantas. Analfabetismo.

\begin{abstract}
The text intends to describe the "intersections between illiteracy and sacrosanct institutions in the "O Example" Journal, printed published in Porto Alegre, state of Rio Grande do Sul (1916-1930)". The time frame resides in the recurrence of the theme of illiteracy and, it is inserted in the field of History of Literacy and History of Education, under the theoretical and methodological assumptions of Cultural History. This assumption suggests prescribing the evidence, the traces, the gaps, the absences and the representations that were built in a given context. The problem, inspired by Geertz's (2008) dense description, reside in the following question: how does illiteracy become a current discourse on the pages of the "O Exemplo" Journal based on sacrosanct institutions: family, society and homeland? The text indicated that the "O Exemplo" Journal undertook a series of efforts so that illiterate people searched for manners to educate themselves for the benefit of the for the good of the country and the progress of the nation.
\end{abstract}

Keywords: "O Exemplo" Journal. Sacrosanct institutions. Illiteracy. 


\section{Introdução}

O presente texto tem a intenção de descrever "as intersecções entre o analfabetismo e as instituições sacrossantas no jornal O Exemplo (Porto Alegre, RS, 1916-1930)". O recorte temporal reside na recorrência da temática do analfabetismo no referido periódico. Cabe registrar que o mesmo foi inicialmente publicado por um grupo editorial negro, mas não exclusivo entre os anos de 1892 a 1930, contando com colaboradores de diferentes origens étnicas. O jornal O Exemplo objetivava ser um 'exemplo' para a comunidade negra recém liberta da escravidão. Assim, suas páginas desejavam imprimiam um novo perfil de homem, mulher e criança na primeira república'.

O texto se propõe a tratar dessa temática em uma perspectiva histórica. Para tanto, foi necessária uma investigação no acervo público que salvaguarda essa documentação², a exemplo do Museu de Comunicação Hipólito José da Costa. Em contato com essa documentação iniciou-se a descrição dos textos publicados no jornal O Exemplo. Cabe apontar que, a pesquisa está situada no campo da História da Alfabetização a partir da compreensão de Mortatti (2000), Frago (1993) e Soares (2004) e da História da Educação em Nóvoa (2015), Stephanou; Bastos (2011) e Faria Filho (2002), sob os pressupostos teóricos e metodológicos da História Cultural, inspirado em Pesavento (2008) e Chartier (1990).

Para Pesavento (2008, p. 42) a "História Cultural seria, pois, decifrar a realidade do passado por meio das suas representações, tentando chegar àquelas formas, discursivas e imagéticas, pelas quais os homens expressaram a si próprios e o mundo". Dessa forma, o presente texto pretende descrever, como as representações sobre o analfabetismo se circunscrevem nas páginas do jornal $O$ Exemplo. A partir dessa orientação, o historiador da educação fará a leitura dos códigos de um outro tempo, o que sugere pensar sobre os discursos construídos em torno dessa temática.

Conforme Chartier (1990, p. 25) indica que "A história cultural trata-se de identificar o modo como em diferentes lugares e momentos determinada realidade social é construída, pensada, dada a ler". O autor também destaca que essa perspectiva teórico-metodológica precisa "considerar os esquemas geradores das classificações e das percepções próprias de cada grupo ou meio como verdadeiras instituições sociais". Nesse sentido, para este texto, procura-se apresentar uma dada realidade criada ou forjada pelos editores e colaboradores do jornal O Exemplo, ou seja, das representações coletivas e individuais sobre a temática do analfabetismo.

Os pressupostos teórico-metodológico inscritos na História Cultural sugere prescrutar os indícios, os vestígios, as lacunas, as ausências, as inércias, as sedimentações e as representações que foram construídas em um determinado contexto por uma ou por várias instituições sociais (CORBIN, 2005; PESAVENTO, 2008; CHARTIER, 1990).

Cabe registrar que, este texto inspirou-se na compreensão do antropólogo Clifford Geertz (2008) quando trata da descrição densa. Desse modo, o texto, não tem uma intenção de análise, mas sim de descrever as representações que foram construídas pelos editores e colaboradores de O Exemplo. Assim, pretende-se dar visibilidade à potência dos textos publicados neste jornal. Isso porque, a historiografia oficial atirou no limbo da história essa produção, nomeada na contemporaneidade de Imprensa Negra.

\footnotetext{
1 Sobre a origem do jornal O Exemplo, seus editores, seus colaboradores, bem como sua relevância para a época, consultar Sousa (2019). O autor elabora quadros e tabelas e, apresenta recortes do impresso que demonstra de forma afinada esses dados.

2 O documento não é qualquer coisa que fica por conta do passado, é um produto da sociedade que o fabricou segundo as relações de forças que aí detinham o poder (LE GOFF, 2013, p. 545). E, continua "todo o documento é ao mesmo tempo verdadeiro e falso, trata-se de pôr à luz as condições de produção e de mostrar em que medida o documento é instrumento de um poder" (LE GOFF, 2013, p. 554)
} 
Ao se debruçar sobre essa documentação impressa do final do século XIX, os pesquisadores tem apresentado indícios, fragmentos e vestígios das diversas tentativas da população negra de instruírem-se, descontruindo o discurso corrente nas páginas dos jornais da época da incapacidade de aprendizagem dos negros.

Neste texto, procurou-se perseguir o seguinte problema: como o analfabetismo torna-se um discurso corrente nas páginas do jornal O Exemplo a partir das instituições sacrossantas? Para uma tentativa de aproximação com o problema de pesquisa, o texto se apresenta a partir de três eixos de discussão: o primeiro, da intersecção da temática analfabetismo e família; o segundo, da intersecção da temática analfabetismo e sociedade; e, terceiro, da intersecção da temática analfabetismo e pátria.

Os três eixos de discussão apresentados vão ao encontro das três instituições sacrossantas, família, sociedade e pátria, presentes nos textos do colaborador Flavius (1917) e de outros, como também da própria editoria, ao indicarem que o jornal $O$ Exemplo empreendeu uma série de esforços para que as pessoas analfabetas procurassem meios de instruírem-se em favor da família, da sociedade e da pátria. Desse modo, tal assertiva só foi possível porque utilizou-se o máximo do conteúdo dos textos publicados pela editoria e por seus colaboradores, analisando-os na perspectiva da descrição densa, aqui, dentro das limitações.

\section{0 analfabetismo e a instituição sacrossanta "família"}

Para tratar da temática proposta, procurou-se agrupar os textos que tematizam sobre o analfabetismo e a família, localizados no jornal O Exemplo. A partir desse exercício, pode-se afirmar que, o texto mais emblemático é do colaborador Flavius (1917) intitulado Contra o analfabetismo. O colaborador toma de empréstimo a frase de Caldas Junior que ressalta: "instrução é o sol das grandes esperanças. O farol que ilumina a alma das crianças". Essa epigrafe contextualiza o momento histórico vivido pelo Governo do Estado do Rio Grande do Sul, que "tem despendido em prol do ensino boa dose de suas energias", quer dizer, recursos para a manutenção de escolas, bem como para o pagamento de professores. Esses esforços tiveram como finalidade a redução do número de analfabetos no estado. Nesse sentido, a alocação desses recursos, indica que a "educação das crianças vai sendo ministrada satisfatoriamente" (O EXEMPLO, 11 de fev. 1917). Baseado nessas informações, o colaborador chama a atenção das famílias, conclamando-as:

Agora o que compete aos pais de família, é não descuidarem no dever de mandar os seus filhos às escolas, a fim de que os mesmos, haurindo na fonte inesgotável da instrução, os conhecimentos necessários para que se tornem aptos para vencerem na vida [...]. O pai que não manda os filhos à escola é um criminoso, que a maior parte das vezes não conhece a intensidade do crime que pratica, nem os resultados maléficos que dele podem advir para os seus filhos, quando tornados homens (O EXEMPLO, 11 de fev. 1917).

Nesse excerto duas questões sobressaem: a primeira, a necessidade de comprometimento dos pais em velarem pela instrução de seus filhos; a segunda, o destaque dado aos graves prejuízos que podem causar a si e à pátria as famílias que lançam à própria sorte os seus filhos. Dessa forma, o que se entende é, por um lado, a posição do colaborador em incutir no âmbito familiar a necessidade de instrução das crianças; e, por outro, a obrigatoriedade dos pais de assegurarem a instrução de seus filhos. Visto que, como indica o texto, o ensino primário é obrigatório e o governo já fez sua parte na abertura das escolas. A esse respeito, Flavius (1917) complementa relatando que essas crianças "vivem por aí acumuladas de energias destruídas, entregues aos vícios e ao crime". Nesse sentido, é enfático quando assegura que essas crianças são vítimas da ignorância, isso porque os pais 
[...] os não obrigaram na época conveniente, a irem às escolas, onde aprendendo e instruindo-se poderiam ter se tornado cidadãos dignos, respeitando, atuando e honrando a família, a sociedade e a Pátria, as três instituições sacrossantas que são como as pedras fundamentais em torno das quais garantiriam a estabilidade e a razão da existência do gênero humano. À pessoa analfabeta é um ente quase que sem utilidade alguma à sociedade, não vive, vegeta, por isso repetimos, o pai que não manda os seus filhos à escola é um criminoso que não imagina talvez o grande mal que prática e por tal crime virá, mais tarde, a ser amaldiçoado pelos próprios filhos (O EXEMPLO, 11 de fev. 1917).

Esse excerto coloca em evidência um pensamento de época: de que a existência do ser humano se organiza a partir de três instituições sacrossantas que ele adjetiva como família, sociedade e pátria. Para Flavius (1917), a pessoa analfabeta era vista como um ser inútil para a sociedade, e os pais que não velam pela instrução de sua prole cometem uma grande falta, não percebem que tal descuido pode acarretar não só a inutilidade do indivíduo, mas também a dissolução dos laços familiares, sendo tal atitude, então contrária à instituição família.

Ao abordar o mal irremediável que provém do inqualificável desleixo de muitos chefes de família que descuram da necessária e imprescindível instrução que deve ser ministrada aos seus filhos na idade apropriada, novamente, em outro texto, intitulado Instrução, o colaborador Flavius (1917) destaca a necessidade de os pais procurarem incentivar junto a seus filhos o amor ao estudo. E sobre isso, assegura:

\begin{abstract}
A nossa estremecida pátria atravessa agora um período áureo de ressurgimento dos sentimentos patrióticos. Mas, decididamente, fora de toda e qualquer controvérsia, somos daqueles que pensam que não pode haver real e verdadeiro patriotismo num país cujo povo seja pouco instruído. Por isso, se faz mister, e jamais nos cansaremos de clamar que todos os srs. pais de família compreendam a necessidade de mandar educar os seus filhos, não só para que eles venham, mais tarde, a ser bons patriotas, extremados defensores da honra e da liberdade do seu país, como, também, para poderem vencer os múltiplos tropeços que, naturalmente, se lhe hão de antepor no percurso da vida (O EXEMPLO, 10 de jun. 1917).
\end{abstract}

O excerto demonstra que a instrução e o patriotismo estão intimamente ligados, pois somente aqueles que possuem elevado grau cultural e intelectual, concorre para o bem da "nossa amada pátria". Logo, sentimentos patrióticos fazem com que Flavius e demais colaboradores incitem nos pais de família a necessidade de instrução dos seus filhos, que "não queiram ser analfabetos". Assim, podem eles, ao mesmo tempo em que cultivam "o amor aos estudos", que tudo melhora e constrói, serem úteis a família.

Flavius (1917) crítica os chefes de famílias que entendem a instrução apenas no domínio do "saber assinar o nome, bem como fazer as quatro operações" e que acreditam que, de posse dessas habilidades, a juventude estará "apta a tirar-se na luta pela vida". Contrariamente, o autor afirma ser este "um erro crasso e detestável" (O EXEMPLO, 10 de jun. 1917). E nessa direção acrescenta:

Todo chefe de família, que bem compreende a grandeza de sua missão no lar, tem a obrigação restrita de mandar educar, convenientemente, os seus filhos, sob pena de, posteriormente, vir a sofrer [...] as censuras justíssimas da sociedade, bem como, as vezes, o desprezo e a maldição dos próprios filhos que, ante os revezes que se the apresentarem na vida, aos quais não possam vencer pela falta da necessária instrução, lançarão sobre os pais a culpa das suas infelicidades, por isso que, na época precisa, foram eles privados de receber o ensino que agora, de muito Ihes havia de servir para minorar as agruras com que, a cada passo, se deparam (O EXEMPLO, 10 de jun. 1917). 
Por um lado, é possível perceber a incumbência dos chefes de família para com a instrução dos seus; por outro, alerta que os filhos, posteriormente, podem desprezar e amaldiçoar seus pais por não terem velado por sua instrução.

Sob essa perspectiva, o texto Sempre pela instrução, de autoria do colaborador F. C. (1918) assegura que "a instrução é o farol que ilumina as almas das crianças". Ao dizer essas palavras, F. C. reúne argumentos para defender sua posição e explica por que muitos chefes de famílias preferem deixam de mandar seus filhos às escolas. A esse respeito, o colaborador tem ouvido respostas como esta: "Ora o meu menino agora está tão bem, ajuda-me tanto: ganha vinte mil reais, como engraxate, vendedor de jornais ou mensageiro" (O EXEMPLO, 26 de mai. 1918). Tal argumento é apresentado para explicar porque para certos pais de família, o trabalho é mais importante do que a instrução, mesmo que o valor recebido pelo trabalho não signifique um valor substancial para a sobrevivência, mas um complemento que o pai julga bem-vindo.

A instrução e o trabalho apresentam-se como condições que assegurariam o desenvolvimento moral e intelectual dos homens de cor e que facilitariam sua integração na sociedade brasileira. Possivelmente, os pais encontravam-se atravessados por esse discurso de que, pelo viés do trabalho seus filhos poderiam ser integrados socialmente. Contudo, deixar de lado à instrução significa a manutenção do número de analfabetos. A esse respeito, o colaborador F. C. (1918) faz a seguinte indagação: é uma "triste ignorância ou torpe desleixo?!" (O EXEMPLO, 26 de mai. 1918). E complementa:

\begin{abstract}
Não se apercebem, por ventura os que raciocinam desta forma, que estão opondo entraves à felicidade dos seus filhos, por isso que, teimando em deixá-los analfabetos, dificultam, enormemente, que eles possam atingir, mais tarde, na sociedade, uma posição, que não diremos de destaque, mas que os ponha a salvo da pobreza, quiçá da miséria. [...] Não compreendem, por acaso, os que resolvem assim, que com a sua imprevidência indesculpável, da qual muitas vezes, fora de tempo, se vem de arrepender, concorrem para tornar os seus filhos, no futuro, cidadãos inúteis a si mesmos, à família, à sociedade e à Pátria?! (O EXEMPLO, 26 de mai. 1918).
\end{abstract}

O argumento apresentado enfatiza uma crítica aos pais de família que insistem em deixar os filhos analfabetos, quer por ignorância, quer por desleixo, pois não percebem que o analfabeto é inútil a si, à família, à sociedade e à pátria. Logo, a condição de analfabeto Ihes dificulta em lograr alguma colocação que Ihes possibilite, minimamente, afastarem-se da miséria.

Os pais e chefes de família têm um compromisso ímpar na formação intelectual do futuro do país. Com essas palavras, o texto Instrução, assinado pela editoria (1918), trata dos esforços do governo do estado, bem como dos municípios, na difusão do ensino popular, isso porque "somente com um povo instruído é que poderemos ser uma nação forte, grande e ditosa" (O EXEMPLO, 01 de abr. 1929). Sob a influência dos princípios positivistas, a editoria (1918) completa:

Resta agora que os chefes de família auxiliem a obra meritória dos nossos governantes enviando às escolas, oficinas do saber, os seus filhos, para que amanhã, sejam dignos da nossa estremecida Pátria [...]. Combater o analfabetismo eis a divisa principal do sincero, do bom patriota. Para o progresso de uma nacionalidade, para o engrandecimento de um povo, a instrução popular é a condição popular. Assim, pois, o caminho é o da Escola, sobretudo (O EXEMPLO, 01 de abr. 1929). 
O excerto indica que a família tem um papel fundamental para o progresso de uma nacionalidade. Isso porque, não se encontra em parte alguma, progresso em uma sociedade em que há analfabetos. Nesse sentido, para combater o analfabetismo, o caminho é o da Escola. Esse espaço institucionalizado, fruto de uma política de modernização do Estado do Rio Grande do Sul que tem como finalidade projetar valores indispensáveis à consolidação do modelo capitalista de sociedade de viés positivista. Dessa forma, para garantir os ideais positivistas, que eram entendidos como a expressão da modernidade no sul do estado, combater o analfabetismo se situava como um caso emergencial. Diante do exposto, naquele período, pensava-se que a família tinha um papel primordial na instrução dos filhos, ou melhor, no afastamento do analfabetismo quando encaminham seus filhos à escola.

\section{0 analfabetismo e a instituição sacrossanta "sociedade"}

O tema do analfabetismo não se circunscreve apenas no âmbito da família, mas também, de toda a sociedade, que tem um papel significativo no incentivar, no estimular e encorajar as pessoas analfabetas a procurem o caminho da escola, da instrução. Dessa forma, para construir um argumento coerente, foi necessário agrupar os textos que versam sobre a relação analfabetismo e sociedade.

Entre esses textos, que tratam de um escopo mais amplo, destaca-se o texto intitulado Pela instrução, escrito pela editoria (1916) de O Exemplo. Neste, a editoria (1916) afirma que a instrução, ou melhor, o analfabetismo continua "a ser entre nós um problema de difícil solução". Medidas tomadas por outros estados da federação mostram que a obrigatoriedade do ensino era o caminho para reduzir os "caldos da ignorância ainda reinantes em nosso país", uma vez que "o que existe em matéria de instrução nada é em vista do tamanho do país e da disseminação de seus habitantes". Contudo, quando apresenta os dados de frequência e matrícula escolar para o Estado do Rio Grande do Sul a editoria informa que este "leva vantagem a muitos outros da União na luta tenaz contra o analfabetismo que é um mal social" (O EXEMPLO, 05 de nov. 1916).

Outro texto relevante de ser apresentado, é intitulado Liga Brasileira Contra o Analfabetismo, escrito pela editoria (1916), o mesmo se propõe a atender à solicitação do coronel Raymundo Pinto Seidl, para publicação de um assunto de interesse do país, pois, confiados no patriotismo de representantes do povo, solicita "apoio, em prol da extinção do analfabetismo em nossa Pátria". Segundo expresso no documento, encaminhado à editoria de $O$ Exemplo solicitando a aprovação de um projeto de lei que tornaria o ensino obrigatório no país, essa ação "muito contribuirá para a solução definitiva desse grande problema nacional", o analfabetismo (O EXEMPLO, 07 de ago. 1921). Visto que, segundo consta no documento:

Nas vésperas do centenário da sua independência política, o Brasil conta ainda $80 \%$ de analfabetos. ISTO É UMA TRISTE VERGONHA, QUE NÃO PODE CONTINUAR!. Sois brasileiros. Certamente amais a nossa Pátria. Vinde, pois, em seu socorro. Ajudai a libertá-la da grande mácula que entorpece o seu progresso. Em nome do Brasil, pedimos o vosso apoio em favor do nosso grande ideal. (Grifos do texto) (O EXEMPLO, 07 de ago. 1921).

A publicação desse assunto demostra que a editoria apoiava o projeto de criação de uma lei para assegurar o ensino obrigatório. Tal obrigatoriedade poderia resultar na redução do número de analfabetos. Ao fazê-lo, demonstra que essa lei poderia contribuir para com a sociedade. 
Esse tema também consta no texto O ensino primário e sua obrigatoriedade, escrito pelo colaborador Mario Gama (1924). Nesse texto, o colaborador trata de como o ensino primário e sua obrigatoriedade podem acabar com o analfabetismo no Brasil, ou seja, podem colaborar para "com a falta de instrução de uns". Conforme Gama (1924):

O Brasil deve cuidar muito do ensino, tanto primário como superior, pois que não pode haver progresso onde existem analfabetos. [...] A campanha ora em vista deve merecer o apoio incondicional, pois é um bem para a sociedade e para o progresso do Brasil. Não pode haver coisa mais bela para um país do que ter os seus filhos devidamente educados, para que, perante os olhos dos estrangeiros, não sejam taxados de ignorantes (O EXEMPLO, 10 fev. 1924).

O excerto sustenta o argumento de que a obrigatoriedade do ensino é indispensável para o bem da civilização. Isso inclui desde o ensino primário até o superior. Com relação ainda ao ensino primário, o autor afirma que afastar as trevas da ignorância que envolvem os analfabetos é uma missão de todos, da nação, dos estados, das municipalidades (O EXEMPLO, 10 fev. 1924).

Sobre a missão de toda a sociedade, em incitar os analfabetos que se instruam, o texto Analfabetismo, escrito pelo colaborador Dario L. Nuncio (1926), ressalta os esforços do governo no sentido de empenhar-se "numa campanha bendita para o desaparecimento do analfabetismo, espalhando pelo território nacional colégios e grupos escolares. Tal fato merece os mais fartos louvores, por isso que a instrução é o principal fator da civilização". A partir dessa constatação o autor afirma: "podermos dizer que o nosso Estado é onde justamente existe a menor porcentagem de analfabetos. Inegavelmente, é um dos tantos frutos de um sábio governo" (O EXEMPLO, 14 mar. 1926). Entretanto, mesmo anunciando para os leitores os esforços do governo para garantir as condições que levassem à erradicação do analfabetismo no estado do Rio Grande do Sul.

No texto O progresso de uma nacionalidade, a instrução popular, a editoria (1928) lembra aos leitores que, incontestavelmente, o progresso de uma nacionalidade resulta da instrução popular. Assim, a instrução popular deve ser assegurada gratuitamente, pois um governo bem-intencionado se esforça para disseminar escolas a fim de que a instrução popular ocorra (O EXEMPLO, 10 dez. 1928). Nesse sentido, a sociedade tem um papel importante nesse desiderato. Segundo a editoria (1928):

No Brasil, entretanto, tem sido descurado esse importante cometimento que tão de perto diz respeito à prosperidade da Nação. Há Estados em que o analfabetismo é inacreditável; a ignorância predomina entre suas populações. Em boa hora, porém, podemos dizer, e com isto ufanarmos, que o Rio Grande do Sul, neste assunto, se encontra pari passu com as unidades mais adiantadas do país (O EXEMPLO, 10 dez. 1928).

A editoria publiciza para toda a sociedade os esforços empreendidos pelo governo do estado na atenção à instrução popular. Esses esforços residem em apagar a ignorância dos analfabetos. Conforme a editoria (1928), "o atual governo gaúcho, que tantos serviços de benemerência vem prestando ao Estado, não tem se descuidado da Instrução, criando novos templos". E tal ação "marcha gloriosamente para um futuro luminoso de progresso" (O EXEMPLO, 10 dez. 1928). Sobre isso, no texto Pela instrução, a editoria (1929) não cessa de publicar conteúdos elogiosos aos feitos do governo do estado e, aqui especificamente, de resolver o analfabetismo no estado. Para a editoria (1929):

O analfabetismo é o pior dos males, o Governo vem disseminando escolas por todos os lugares, os mais recônditos, a fim de que a instrução, qual sol radioso, deixe seus raios luminosos penetrarem em todos os lares. E, para esse desiderato, não tem poupado esforços, aumentando a respectiva verba, para que diminua, o mais rápido possível, o número de analfabetos (O EXEMPLO, 04 de fev. 1929). 
Essa referência demonstra que as ações do governo do estado estão vinculadas ao aumento de verbas para redução do número de analfabetos, o "pior dos males" que podem ser adjetivados como: atraso, sujeira, feiura, doença, ignorância, prostituição, loucura, vadiagem, ou seja, a desordem que deveria ser eliminada. Nesse sentido, toda a sociedade tem um papel fundamental para com os analfabetos, de incentivá-los e ajuda-los a instruírem-se.

\section{0 analfabetismo e a instituição sacrossanta "pátria"}

Para essa discussão, foram agrupadas as temáticas do analfabetismo e pátria recorrentes no jornal O Exemplo. Sobre essa relação, o texto intitulado Os preconceitos na instrução, escrito pela editoria (1916), sinaliza a importância da "unificação social de todos os brasileiros", inclusive das "meninas de cor" que foram excluídas das "homenagens à Independência Pátria" pelo Dr. Clemente, conforme destacado pelo periódico A Noite e reforçado pela editoria de O Exemplo (O EXEMPLO, 10 de set. 1916).

A editoria argumenta que a figura do Dr. Clemente não revela um espírito patriótico, apesar da sua condição de educador, concorrendo assim para o rebaixamento pátrio da nação brasileira, ao excluir analfabetos, uma vez que, uma pátria reconhecida por todos é uma pátria que dispensa instrução a todos os filhos da terra. Dessa forma, para que, de fato, a instrução seja um motor do desenvolvimento da pátria, é necessário desenvolver campanhas contra o analfabetismo. Nesse sentido, no texto intitulado Contra o analfabetismo, a editoria (1916) de O Exemplo ressalta que:

Em vários Estados têm-se criado associações em auxílio dessa ideia de tão alevantados benefícios. Em S. Francisco de Paula de Cima da Serra acaba de ser fundada uma Liga Contra o Analfabetismo cujos estatutos já estão sendo elaborados. Por ocasião da fundação feita em uma assembleia geral, foi lida a seguinte moção que abrirá os estatutos: "É grande empenho da Liga conseguir que não haja em Cima da Serra nenhum menor em idade escolar que não tenha frequentado uma aula até 7 de setembro de 1922, centenário da Independência da Pátria" (O EXEMPLO, 10 de dez. 1916).

Os esforços contra o analfabetismo sinalizam o comprometimento de espíritos patriotas para com o desenvolvimento da nação. Demonstram que ações como essas tornariam possível, no menor espaço de tempo, até o centenário da Independência, promover a frequência de menores no espaço escolar. De acordo com a editoria (1917), a forma com que o tema do analfabetismo é tratado no estado de São Paulo poderia contribuir para que o estado do Rio Grande do Sul pudesse se espelhar e empreender esforços para que o analfabetismo fique apenas no passado, como é possível visualizar no texto escrito pela editoria (1917):

Com a louvável e patriótica intenção de ser dada perfeita interpretação à lei que estabelece a obrigatoriedade do ensino preliminar, São Paulo acaba de construir uma grande comissão que se encarregará de levantar este ano a estatística escolar de suas cidades. Além da estatística das crianças em idade escolar, a referida comissão enviará esforço para conseguir a afluência da matrícula nos grupos e escolas. Como se vê, é uma ideia patriótica e que merece francos aplausos (O EXEMPLO, 21 de jan. 1917).

A partir desse exemplo, a editoria sugere que "os governos estaduais hajam com as mesmas patrióticas medidas". Segundo a editoria, essa é, pois, uma ação inteligente por meio da qual "nasce o combate em favor da instrução e contra o 'monstro' do analfabetismo, terrível cancro que aí está a roer todas as energias salutares do progresso e bem-estar futuro da Pátria" (O EXEMPLO, 21 de jan. 1917). 
Com relação a esse tema, o texto De quando em vez... Contra o analfabetismo, escrito pelo colaborador Flavius (1917) externa essa mesma preocupação e, para colaborar na discussão, destaca a atitude do Japão frente a esse problema, pois os "dirigentes da instrução pública no Japão" têm "incentivando nos alunos o gosto pelos estudos". Esse "procedimento, altamente louvável [...] podia ser imitado aqui no Brasil, onde, infelizmente, a educação da infância é muito descuidada" (O EXEMPLO, 11 de mar. 1917). Nesse sentido, travar guerras contra esse "monstro" que é o analfabetismo é um dever de todo o bom patriota.

Nessa direção, o texto Rumo aos livros, o colaborador, sob a assinatura M.F. (1919) aborda que travar "guerra contra o analfabetismo" continua a ser uma pauta necessária e de urgência para sua resolução. Pois, enquanto não se houver, de fato, suprimido esse mal da sociedade, as "sombras da ignorância" continuarão a habitar "nossa querida pátria". Diante disso, argumenta não compreender o porquê de um problema de tanta magnitude, como o analfabetismo, não houvesse há mais tempo preocupado seriamente os dirigentes deste país. A esse respeito, M.F. (1919) sugere pensar o analfabetismo sob três perspectivas: a primeira, culpabiliza os dirigentes dos demais estados da federação quanto ao descomprometimento de instruir seu povo; a segunda, não compreende como, apesar das iniciativas particulares, ainda persiste o analfabetismo; a terceira, coloca em evidência que os dirigentes do estado do Rio Grande do Sul têm empreendido esforços contínuos para oferta de instrução, bem como têm trabalhado para a "redução cada vez maior que conseguirmos na porcentagem do analfabetismo" no seu vasto território (O EXEMPLO, 13 de abr. 1919). De acordo com M.F. (1919):

Aos nossos irmãos em raça prestaria serviço de alta relevância quem, possuidor de elevada cultura e vasta erudição, desferindo de sua acerada pena golpes persuasiva e convincentemente, conseguisse incutir no ânimo dos que se obstinam em permanecer no obscurantismo a necessidade palpitante que temos de reunir todas as nossas forças e oferecemos combate sem tréguas ao analfabetismo ( $O$ EXEMPLO, 13 de abr. 1919).

Através deste impresso, M.F. (1919) sinaliza a importância de um trabalho de todos os patriotas, na tentativa de incutir, nos "cérebros obscurecidos pelas trevas da ignorância", "o gosto pelos estudos". Ao empunhar "armas contra o analfabetismo", será possível o exercício da democracia. Essa seria, então, "uma das maiores conquistas da democracia [que] é a universalização de voto", direito que, no período investigado, a "Constituição da República conferiu a todos os cidadãos que soubessem ler e escrever". Assim, ao excluir o analfabeto, ele "ficou assim proscrito na sua própria pátria, considerado indigno de usar de prerrogativas só conferidas aos que fossem nos livros buscar a base dos seus direitos constitucionais". Com esse discurso, M.F. (1919) entende que o exercício desse direito seja concedido a todos aqueles que, com "elevada cultura e vasta erudição", possam encaminhar toda a nação, ou dito de outra formam, "possam inaugurar em nossa pátria uma era de franca prosperidade e de progresso como ela tanto merece" (O EXEMPLO, 13 de abr. 1919). Em outro texto também intitulado Rumo aos livros, M.F. (1919) afirma que a grandeza da Pátria será realizada quando estiver extinto o analfabetismo no país, bem como aponta que "a guerra contra o analfabetismo vai [seguindo] vitoriosamente", de modo que, "se continuar a ser conduzida como o está atualmente, é de prever-se que em breve tempo haja atuado eficazmente por todos os recantos deste vasto país" (O EXEMPLO, 18 de mai. 1919). 
Em seguida, no último texto, Rumo aos livros, M.F. (1919) trata da Liga Central Pró-Infância Desvalida, fundada por mulheres de Porto Alegre. Segundo M.F. o principal objetivo desta liga é "incitar o amor às crianças analfabetas" ao estudo. A partir desse fragmento, é possível compreender a colaboração que as mulheres podem oferecer à pátria. Nesse sentido, investir em sua instrução é um dever pátrio, haja visto que relevantes serviços, como esse, dos cuidados com as crianças desvalidas, poderão ser realizados para esta "gloriosa pátria", em especial, compromisso de erradicar o analfabetismo. De modo geral, em uma pátria que anseia por ser grande, é necessário que homens e mulheres dispensem um "pequeno sacrifício: não queiram ser analfabetos, aprendam a ler e escrever, instruam-se em suma" (O EXEMPLO, 08 de jun. 1919). Nessa direção, o texto Delenda Cahthago, escrito pelo colaborador Mario Pinto Serva (1924), discuti o estado de abandono educativo e sugere combater o analfabetismo. Segundo Serva (1924):

\begin{abstract}
É preciso levantar no Brasil todo um imenso clamor, de todos os peitos, para que todos se movam, para que os poderes públicos, municipais, federais e estaduais, para que todas essas iniciativas particulares entrem decididamente nessa campanha, que é agora a única forma porque deve manifestar-se o patriotismo no Brasil. Tudo mais nos virá de acréscimo. Saúde, riqueza, poder, prosperidade, tudo nos será outorgado pela educação e na razão direta do vigor com que combatermos o analfabetismo e com que intensificarmos a cultura nacional sob todos os pontos de vista e com aplicação a todas as necessidades da vida (O EXEMPLO, 21 de dez. 1924).
\end{abstract}

As palavras expressas pelo colaborador apontam que o levantamento da pátria só acontecerá se todos trabalharem na campanha contra o analfabetismo, dado que seu engrandecimento é fruto de uma pátria instruída. Nesse sentido, todos os espíritos patriotas precisam cooperar para uma nação engrandecida de seus feitos. Nessa perspectiva, no texto A instrução pública, a editoria (1928) aborda que "a instrução pública é, incontestavelmente, a maior necessidade do povo" (O EXEMPLO, 05 de fev. 1928) e que tal necessidade vinha sendo suprida, pois, de acordo com a editoria, o estado "marcha na vanguarda, com respeito à instrução popular", posto que nele se encontra o "menor número de analfabetos", sendo "motivo de júbilo para os rio-grandenses" (O EXEMPLO, 05 de fev. 1928). Segundo o corpo editorial de $O$ Exemplo, essa nota promissora enche de satisfação a todos os bons patriotas que perceberem as ações desenvolvidas pelo Estado rumo ao progresso. Desse modo, um povo alfabetizado se notabiliza na grandeza da Pátria, no futuro da nacionalidade.

\title{
Considerações
}

Para um arremate, cabe registrar que, este texto objetivou descrever as intersecções entre o analfabetismo e as instituições sacrossantas no jornal O Exemplo, um impresso publicado no estado do Rio Grande do Sul, no município de Porto Alegre, entre os anos de 1916 a 1930. O recorte temporal, situado no texto, residiu na recorrência da temática do analfabetismo que, inscrito no campo da História da Alfabetização e da História da Educação, sob os pressupostos teóricos e metodológicos da História Cultural prescrutou os indícios, os vestígios, as lacunas, as ausências e as representações que foram construídas nesse período.

O conjunto de textos investigados, sinaliza o entendimento de que, com relação a intersecção da temática do analfabetismo e família, a ignorância dos pais é evidente quando estes não velam pela instrução dos seus filhos, quando não percebem que a instrução poderia torná-los cidadãos dignos. Isso porque ainda não compreenderam que a pessoa analfabeta é um ente quase sem utilidade à sociedade. 
Ao descuidar da instrução, bem como de enviar seus filhos à escola, podem ser considerados criminosos e podem, futuramente, ser amaldiçoados pelos próprios filhos. Dessa forma, O Exemplo empreendeu esforços para que os pais incentivassem seus filhos o amor ao estudo para que não sejam analfabetos e possam vencer os múltiplos tropeços que a vida impõe.

Na intersecção da temática analfabetismo e sociedade, os textos indicam que todos devem cooperar com a instrução do povo. Assim, sinalizaram a importância de exigir dos governantes que disseminem o ensino primário por todo o país, auxiliando as escolas mantidas por particulares e associações e assegurando gratuitamente a instrução popular, que levaria, então, a solução definitiva do analfabetismo, bem como os caldos da ignorância ainda reinantes no país. Nesse intento, demostrou-se o entendimento do periódico de que, não pode haver progresso onde existem analfabetos. Dessa forma, as campanhas contra o analfabetismo foram, seguramente, relevantes para incitar o povo a instruir-se. Uma vez que, a grandeza da raça só é alcançada em uma sociedade sem analfabetos.

Em relação a intersecção da temática analfabetismo e pátria, as recorrências apontaram para a importância da unificação social de todos os brasileiros, bem como para a necessidade de empreender campanhas contra o analfabetismo para o desenvolvimento e progresso da pátria. Esse discurso foi longamente difundido, pois o levantamento da pátria só acontece se todos trabalharem na campanha contra o analfabetismo. Isso fica evidente quando se compreende o analfabetismo como um terrível cancro que corrói as energias do progresso e o futuro bem-estar da pátria. Logo, o texto indicou que a grandeza da pátria só será realizada quando estiver extinto o analfabetismo e quando todos aprenderem a ler e a escrever. Finalmente, indica que a instrução é o motor do desenvolvimento da pátria.

Por fim, cabe ressaltar que, a temática do analfabetismo, articuladas as três instituições sacrossantas, família, sociedade e pátria, como referidas por Flavius (1917) foram temas recorrentes pela editoria e seus colaboradores. Esses esforços residiram em incitar os analfabetos a procurarem meios de instruírem-se para o bem da família, da sociedade e da pátria.

\section{Referências}

CORBIN, Alain. O prazer do historiador. Rev. Bras. Hist. 2005, vol.25, n.49.

CHARTIER, Roger. A história cultural: entre práticas e representações. Lisboa: DIFEL, 1990.

FARIA FILHO, Luciano Mendes de. O jornal e outras fontes para a história da educação mineira do século XX: uma introdução. In: ARAÚJO, José Carlos Souza; GATTI JR, Décio (org.). Novos Temas em História da Educação Brasileira: instituições escolares e educação na imprensa. Campinas, SP: Autores Associados, 2002.

FRAGO, A.V. Alfabetização na sociedade e na história: vozes, palavras e textos. Porto Alegre: Artes Médicas, 1993.

GEERTZ, Clifford. Uma descrição densa: por uma teoria interpretativa da cultura. In: A Interpretação das culturas. Rio de Janeiro: Zahar, 2008.

LE GOFF, Jacques. História e memória. 7ed. Campinas, SP: Editora da Unicamp, 2013.

MORTATTI, Maria do Rosário Longo. Os sentidos da alfabetização. São Paulo: Editora UNSP: CPNED, 2000.

NÓVOA, António. Carta a um jovem historiador da educação. História y Memoria de la Educación, Sedhe, n. 1, 2015, p. 23-58.

O EXEMPLO (1894-1919). Disponível em: http://bndigital.bn.br/acervo-digital/exemplo/843717. Acesso em 15 de abr. 2020. 
O EXEMPLO (1920-1930). Disponível em: http://ihgrgs.org.br/. Acesso em 15 de abr. 2020.

PESAVENTO, Sandra Jatahy. História e história cultural. 2 ed. Belo Horizonte: Autêntica, 2008.

SOARES, M. Letramento e Alfabetização: as muitas facetas. Revista Brasileira de Educação, n. 25, p. 5-17, jan./ abr. 2004.

STEPHANOU, Maria; BASTOS, Maria Helena Camara (orgs). Histórias e memórias da educação no Brasil, vol III: século XX. 4 ed. Petrópolis, Rio de Janeiro: Vozes, 2011.

Recebido em: 09/12/2020

Aceito em: 25/05/2021 